\title{
The Legal Application of Either-or Choice of E- commerce Platforms: Taking the Case of Alibaba Group as an Example
}

\author{
Ruonan $\mathrm{Yu}^{1, *}$ \\ ${ }^{1}$ Faculty of Law, Kunming University of Science and Technology, Kunming, Yunnan 650500, China \\ *Corresponding author. Email: yurn1812@163.com
}

\begin{abstract}
This paper summarizes the current legal provisions that can regulate Either-or Choice behavior on e-commerce platforms and, taking Alibaba Group as an example, analyses the penalty decision letter issued by the China State Administration for Market Regulation against Alibaba Group to explore the ideas of law enforcement agencies in regulating Either-or Choice behavior. It can be concluded that establishing and improving the legal mechanism for whether Either-or Choice behavior is illegal. Improving the legal regulation of Either-or Choice behavior on e-commerce platforms should first clarify the criteria for Either-or Choice behavior to be illegal; secondly, Article 35 of the E-commerce Law should be improved, and finally, the legislature should clarify the procedure for law enforcement to initiate the definition of Either-or Choice behavior to be illegal.
\end{abstract}

Keywords: E-commerce platform, Either-or choice, Platform to business.

\section{INTRODUCTION}

E-commerce platform Either-or Choice behavior, which means the e-commerce platform through the implementation of its platform merchant traffic blocking, search downgrading, and direct offline merchants to disrupt merchants operating on other ecommerce platforms.

There is no unified standard for determining the Either-or Choice behavior of e-commerce platforms in Chinese judicial practice and academic circles. Above all has been a hot topic of discussion in recent years. However, the legal application of this act is mainly absent from the English academic literature. Up to now, most studies focused primarily on the interaction between the Information Communication Technology (ICT) innovation and the E-commerce industry growth and the presentation of macro legal policies.[1] This paper attempts to fill this lacuna by using the case of Alibaba Group, which was fined 18.2 billion on April 10, 2021, as an example, to analyze the criteria used by China's administrative authorities to determine the Either-or Choice behavior of e-commerce platforms. And then explore how the law should be applied in the future when determining the Either-or Choice behavior of ecommerce platforms.

\section{STATUS OF REGULATION OF EITHER-OR CHOICE BEHAVIOR ON E-COMMERCE PLATFORMS}

Since the war between Tencent QQ and Qihoo 360 in 2010, the practice of Either-or Choice on ecommerce platforms has existed in China. After the enactment of the E-Commerce Law of the People's Republic of China in 2019, there are currently three laws that the judiciary can apply in dealing with cases in this area, namely Article 35 of the E-Commerce Law, Article 12 of the Anti-Unfair Competition Law, and Article 17 of the Anti-Monopoly Law. Although all three laws can regulate "second-choice" conduct, they differ in their areas of application, standards of application, and legal consequences. Not all Either-or Choice acts will meet the normative elements of the three laws. Even if they formally do, they may not all be applicable, and the choice to apply different rules may have other implications and even present a difference in merit.[2] 


\subsection{The Advantages and Disadvantages of Applying the E-commerce Law}

The E-commerce Law is a specific law of the Chinese government regulating commercial trading relationships between enterprises and individuals through electronic acts using data messages to the transaction. In terms of the regulation of Either-or Choice behavior on e-commerce platforms, it has the advantage of being highly targeted.

There are three limitations. Firstly, the concept of unreasonable, as referred to in Article 35 is rather vague and is easily influenced by the subjectivity of the enforcers in enforcement practice.[3] The book Interpretation of the Electronic Commerce Law of the People's Republic of China, edited by the drafting group of the Electronic Commerce Law, titles Article 35 as Prohibition of abuse of dominant position. However, the legislator did not set any conditions for establishing the dominant position of the platform operator, thus expanding the scope of adjustment and the target of Article 35.[4] Secondly, it is less operable. The E-Commerce Law only sets administrative penalties without civil liability, which may increase the enforcement burden of the grassroots enforcement authorities and restrict merchants from using civil remedies. Thirdly, the legal liability is relatively light, as the maximum fine set by the E-commerce Law for Either-or Choice conduct is RMB 2 million, which is hardly a deterrent to platform operators.

\subsection{The Advantages and Disadvantages of Applying the Anti-Unfair Competition Law}

The subjects regulated by the anti-unfair competition law are operators and consumers in the socialist market economy. Thus, the advantage of using the anti-unfair competition law to regulate Either-or Choice conduct on e-commerce platforms is that Article 12 sets out clear criteria for its application, which for behavior that restricts competition.

In contrast, the first disadvantage is the Narrower scope of application, mostly to unfair competition in traditional areas. The second disadvantage is that it is difficult to identify Either-or Choice behavior, as Article 12 of the law is premised on applying technical means, but e-commerce platforms are themselves based on technical means of Internet transactions. The third disadvantage is that the legal liability is relatively light, as subjects who violate the law against the unfair competition will be ordered by the administrative authorities to stop the illegal acts and pay a fine of up to RMB 3 million. However, this is a relatively light penalty for companies that may have engaged in Either-or Choice behavior and will not have the effect of serving as a warning.

\subsection{The Advantages and Disadvantages of Applying the Anti-Monopoly Law}

The anti-monopoly law is the most general law in the field of restrictive competition. It has the advantage of being applied in principle to all market sectors when regulating Either-or Choice conduct, in addition to which the anti-monopoly law has the advantage of imposing penalties from $1 \%$ to $10 \%$ of annual sales for some industry oligopolies, which is an excellent solution to the problem of insufficient penalties in the E-commerce law and the anti-unfair competition law.

However, the threshold of application of antitrust law is high. The anti-monopoly law regulates conduct that undermines the competitive mechanism of the market, which is more illegal. Therefore, the antimonopoly law sets a heavier legal liability for the perpetrators.

According to Article 17, the premise for determining that the Either-or Choice e-commerce platform is an abuse of a dominant market position and a violation of the Anti-Monopoly Law is that the platform operator occupies a dominant market position.[5] To determine that the platform operator occupies a dominant market position, the administration must define the relevant market. There is a current view in Chinese competition law that the digital economy, as a new driving force for global economic growth, is characterized by cross-border competition, network effects, and platform competition, and that the anti-monopoly analysis applicable to the traditional economy cannot be applied in the Internet industry.[6]

This paper agrees with the prevailing view in the academic community that Either-or Choice behavior is prevalent when large enterprises commit it or when the perpetrator does not necessarily have substantial market power.[7] The following sections will address the issue of market dominance using the Alibaba Group as an example.

\section{THE CASE OF ALIBABA GROUP}

In April 2021, China State Administration for Market Regulation imposed a fine of RMB 18.228 billion on Alibaba Group, an amount rarely seen in 
the history of Chinese commerce. The penalty was imposed based on the Anti-Monopoly Law, which is of guidance in discussing the application of the law on Either-or Choice e-commerce platforms. There are still many Either-or Choice in Chinese practices, so it is necessary to learn from this experience and establish standards to regulate Either-or Choice practices as soon as possible.

\subsection{Dominant Position in the Relevant Market}

The key to the application of antitrust law, in this case, is the determination of market dominance. Since it has a dominant position in the relevant market, whether the Alibaba Group abuses its dominant position is vitally important.

If the government wants to identify whether a certain platform is dominant in the market, it should first define the scope of the relevant market. The relevant market is negatively correlated with market dominance, i.e., the greater the scope of the relevant market, the less likely it is that the operator has a dominant market position. Relevant markets include relevant commodity markets and relevant geographic markets. The State Administration for Market Regulation identified the relevant commodity marketplace of Alibaba Group Inc. as an online retail platform service marketplace, which is a bilateral platform, with the Taobao platform providing online business premises, transaction aggregation, and other platform intermediary services, during the Taobao platform service targets sellers and buyers. At the same time, the State Administration for Market Regulation used operator demand substitution analysis, consumer demand substitution analysis, and supplier substitution analysis to argue that the online and offline markets for retail platform services are not the same market.

In turn, offline supermarket chains (Wal-Mart, Carrefour), providing retail platform services, are not

Table 1. Alibaba's share of combined service revenue from 10 major e-tailing platforms within China

\begin{tabular}{|l|l|l|l|l|l|}
\hline & 2015 & 2016 & 2017 & 2018 & 2019 \\
\hline $\begin{array}{l}\text { Revenue from e- } \\
\text { tailing platform } \\
\text { services }\end{array}$ & $86.07 \%$ & $75.77 \%$ & $78.51 \%$ & $75.44 \%$ & $71.17 \%$ \\
\hline Platform turnover & $76.21 \%$ & $69.96 \%$ & $63.58 \%$ & $61.70 \%$ & $61.83 \%$ \\
\hline
\end{tabular}

As shown in "Table 1", Alibaba Group's share of platform service revenue and platform merchandise transactions from $2015-2019$ is well over $50 \%$. In fact, an operator is presumed to have a dominant market position as long as it meets the Article 19 the same relevant goods market as Taobao. The State Administration for Market Regulation found the geographical market where Taobao operates to be a market within China on four grounds. The first and second of these reasons are argued by using the Analysis of Demand Substitution. As for the first reason, the department mainly based on the rule of thumb, based on life experience and the interview transcripts of the relevant personnel of the platform operators for supporting evidence, inferred that online sellers want to sell goods to Chinese buyers through the Internet, generally will not choose overseas e-tailing platforms (such as Amazon, eBay, Rakuten, etc.). However, it is a rule of thumb judgment without objective, large statistical data, and other evidence to support the reliability and persuasiveness of the assertion face specific problems. The third and fourth reasons explain why the relevant market is within Chinese territory and not outside China and in a particular province or block within China.

\subsection{Market Dominance of Alibaba Group}

Having defined the relevant market in which Alibaba operates, it is then necessary to determine whether Alibaba is in a dominant position in the relevant market to conclude whether it has engaged in monopolistic conduct in the form of abuse of market dominance.

Article 18 and 19 of the Antimonopoly Law sets out the factors determining that an operator has a dominant market position. The China State Administration for Market Regulation considers that an analysis to determine whether a party has a dominant market position requires careful consideration of the relevant factors stipulated in the law. Alibaba Group has long held a high market share and has a high degree of market recognition.

market share criterion of $50 \%$. However, the State Administration of Market Supervision and Administration also analyses the concentration of the relevant market. The Herfindahl-Hirschman Index and the Concentration Ratio 4(Market Concentration 
Index), are used as essential criteria for determining a high degree of concentration in the relevant market, taking into account the company's market share, market recognition, and consumer stickiness.

Table 2. Market share of platform services revenue

\begin{tabular}{|l|l|l|l|l|l|}
\hline & \multicolumn{1}{|c|}{2015} & \multicolumn{1}{|c|}{2016} & \multicolumn{1}{c|}{2017} & \multicolumn{1}{c|}{2018} & \multicolumn{1}{c|}{2019} \\
\hline HHI & 7408 & 6008 & 6375 & 5925 & 5350 \\
\hline CR4 & 99.68 & 99.46 & 98.92 & 98.66 & 98.45 \\
\hline
\end{tabular}

As shown in "Table 2", Alibaba Group has a high HHI and CR4 index in the e-tailing platform services market from 2015 to 2019, which indicates that the party has a low number of competitors and has a solid competitive advantage in the long term.

\subsection{Analysis on Whether Alibaba Abuses Its Dominant Market Position}

The penalty decision of the State Administration for Market Regulation against Alibaba Group reflects the spirit of the Anti-monopoly Guidelines of the Anti-monopoly Commission of the State Council on the Platform Economy. The Guidelines clarify that the determination of abuse of dominant market position in the platform economy usually requires defining the relevant market, analyzing whether the operator has a dominant position in the relevant market, and then analyzing whether it constitutes an abuse of dominant market position on a case-by-case basis. The Guide details the forms of abuse of market dominance, such as unfair pricing practices, selling below cost, refusal to deal, limited trading, tying and differential treatment with unreasonable trading conditions, to promote compliance with the law by various market players in the platform economy.

In the case of Alibaba Group, it was already in a dominant position in the market. It has committed an abuse of its dominant position - i.e., it has committed an Either-or Choice act of limiting the counterparty to trading with it without justifiable reasons, as evidenced by,

First, it is to restrict and prohibit core sellers stationed on the Taobao platform from opening shops or participating in promotional activities on other platforms through agreements and verbal means.

Second, a variety of incentives and penalties are in place to safeguard the implementation of the above restrictions.

In the light of the above, the State Administration of Market Supervision concluded that Alibaba Group had engaged in an Either-or Choice campaign.

Finally, the State Administration of Market Supervision and Administration imposed a fine of $4 \%$ of the previous year's sales on Alibaba Group, which constituted an abuse of a dominant position in the market, taking into account the nature, extent, and duration of the conduct. While the anti-monopoly law stipulates a fine of $1 \%-10 \%$ of the previous year's sales, the State Administration of Market Supervision and Administration set the fine at $1 \%$ less than the mid-point, which reflects discretion and China's encouragement of the healthy development of the platform economy.

\section{CONCLUSION}

The penalty imposed by the State Administration of Market Supervision and Administration on Alibaba Group is a typical case since the introduction of China Anti-monopoly Law and is of guidance. Since China's anti-monopoly judicial practice started late, it still needs to be improved in the following three aspects:

Firstly, the criteria for applying the law on Eitheror Choice to different types of e-commerce platforms should be further clarified, not only operators in a dominant market position have Either-or Choice It is not the case that only operators in a dominant position in the market have the right to Either-or Choice, as some small-scale platforms may have such problems. Some small-scale platforms may have such problems. The way to clarify the application of the law is to issue judicial interpretations and guiding cases. Secondly, the e-commerce law is special in the field of the platform economy, but the academic community generally believes that the provisions of Article 35 are too principled and sloppy. The conditions of application are too lenient, which may easily lead to the relevant provisions in the competition law being completely hollowed out, so it needs to be corrected, i.e., those who apply the law should implant the theory of abuse of relative dominance into the article to give it the true character of anti-unfair competition law. Thirdly, the legislature should clarify the procedure for law enforcement to initiate the definition of Either-or Choice behavior to be illegal. The investigation of Alibaba Group by the State Administration of Market Supervision and Administration was initiated by 
receiving reports. However, most merchants in a truly vulnerable position do not dare or can report platform violations to the Market Supervision and Administration. Therefore, a complaint mechanism for merchants should be established to give some protection to merchants in a vulnerable position in ecommerce platforms.

\section{AUTHORS' CONTRIBUTIONS}

This paper is independently completed by Ruonan $\mathrm{Yu}$.

\section{ACKNOWLEDGMENTS}

This research was made possible thanks to the help, support, and encouragement of my parents and thesis teacher, Min Han, without whom it would have been difficult for me to complete this paper.

\section{REFERENCES}

[1] You Chuanman, Law and policy of platform economy in China, Computer Law \& Security Review, 2020(39),105

[2] Jiao Haitao, Judicial Application and Analytic Method for the Exclusive Dealing of ECommercial Platforms, China Review of Administration of Justice, 2020,(01),49-62.

[3] Dai Long, Applicable Research on the Regulation of Abuse of Dominance in the Ecommerce Law, Price: Theory \& Practice, 2019,(02),28-32.

[4] Zhu Li, Zeng Youlin, The Connection of Ecommerce Law and Laws about Competition: System Logic and Future Enforcement, Journal of Graduate School of Chinese Academy of Social Sciences, 2019,(02),104-112.

[5] WANG Xiaoye, The Functioning and the Roles of the Market Definition in Antitrust Cases Involved Abusive Behaviors, Modern Law Science, 2018,40(03),57-69.

[6] WANG Xiaoye, The Legal Regulation of Either-or Choice of Online Platforms in ECommerce, Modern Law Science, 2020,42(03),151-165.

[7] Jiao Haitao, Judicial Application and Analytic Method for the Exclusive Dealing of ECommercial Platforms, China Review of Administration of Justice, 2020,(01),49-62. 